\title{
A BOTTLE-NECKED LEMON
}

\author{
Leonhardt Swingle, Riverside, Cal.
}

$\mathrm{T}$

HE work of A. D. Shamel on bud sports and their occurrence in the citrus family has directed much attention recently to this class of variation. It is now recognized that such sports are more frequent and are of greater importance from the standpoint of improving and standardizing varieties than has been recognized before this time. A slight examination of almost any citrus orchard will usually disclose many cases of sporting limbs and demonstrate the need of further investigations on this subject.

The writer recently found in a Eureka lemon orchard near Corona, Cal, a tree bearing a large and very unusual limb sport. This branch has been overlooked in pruning until at the present time it comprises a large part of the tree. The whole limb is of a peculiar type as shown by the fruit, leaves, and habit of growth. It is very different from the remainder of the tree, which is to all appearances a normal Eureka lemon.

The fruit, as shown by the accompanying illustration, is at once distinguished by its long, bottle-like neck and its small size. It is a lemon but with the shape of a gourd. The limb is sufficiently productive, if the crop it now bears can be taken as a criterion, but lemons of this peculiar gourd-like shape are not worth much in the market today. This large limb and its crop of worthless lemons may be considered as so much detriment to the tree for it is occupying space and using plant food that might as well be used in the production of good fruit. The limb is a boarder instead of a producer.

As brought out in the illustration, the leaves of this limb are very different from those of the normal Eureka lemon. They are narrow and sharply pointed, resembling willow or peach leaves more than those of the remainder of the tree.
These narrow leaves give a distinctive appearance to the side of the tree where this limb is located, although this difference in appearance is emphasized by the more slender and dense twig growth.

The narrow pointed leaves and "bottle-neck" fruit constitute a distinct and unusual type. There is no transition between the normal part of the tree and the sporting branch. There is a small twig on the sporting limb near its base, that bears normal Eureka lemons, while a short distance above is another twig bearing the "bottle-neck" fruit. Somewhere between the two twigs the change occurred from the normal to the freakish fruit.

The discovery of this limb encouraged the writer to make a search for others of a similar nature on other trees of the same grove. Several have been found varying in degree from large limbs similar to that described, to mere twigs.

It is interesting to note that there is an apparent correlation between the "bottle-neck" fruit and the narrow, pointed leaves Where the leaves are narrow and pointed, the fruit is usually of this pronounced "bottle-neck" shape. This apparent relationship indicates that the value of a branch might sometimes be judged by its leaves, when pruning or cutting buds.

The discovery of such limb sports while still twigs makes it possible to cut them out before they reach a large size and lower the value of the trees by their production of worthless fruit. It is, of course, best to grow only trees which do not produce such Ireakish limbs. The next best thing is to keep such limb variations in trees under control by cutting them out with the pruning knife so that their erratic tendencies may be checked so far as possible. 


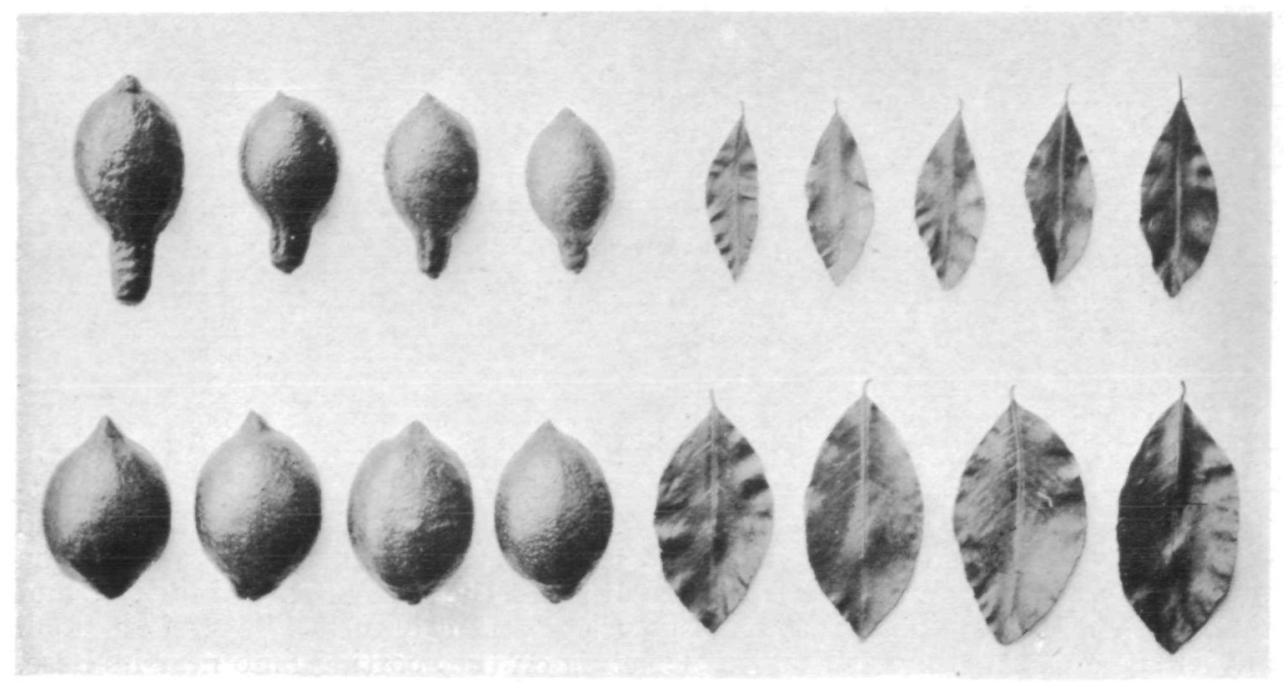

\section{BOTTLE-NECKED AND ORDINARY EUREKA LEMONS}

A limb-sport was found in a lemon tree, which gave rise to lemons of the peculiar shape shown at the top of the photograph. The effect of the change was not confined to the fruit, but extended also to the leaves, which are much narrower than ordinary. Normal fruit and leaves, borne by the unchanged part of tree, are shown at the bottom of the photograph. The marked change in leaves and fruit is a good illustration of the fact that variability is correlated, and that one part of an organism cannot be markedly changed without producing changes in various other parts. (Fig. 8.)

\section{The Number of Unmarried Persons in the United States}

There are $17,000,000$ celibates in the United States, according to a statement which has been going the rounds of the press, after originating in a magazine article on the sex question. Examination of the census schedules for 1910 indicates that this figure includes all males over 20 and all females over 15 . A calculation based on such age limits is misleading, but the actual facts are quite striking enough. Persons 35 years of age or over are relatively unlikely to marry, and it seems fair to base computations on that age. They show, then, that there are nearly $2,000,000$ un- married men in the population, and about 1,250,000 unmarried women. There are about $1,500,000$ unmarried women between the ages of 25 and 34 , and a considerable part of these are certain never to marry. The celibacy of these millions is, from a eugenic point of view, not wholly to be deplored. While the number includes many potential fathers and mothers of a desirable character it is probable that, on the whole, these life-long celibates are eugenically inferior to the married population.

\section{Pure-lines of Bacteria}

From studies 'of bacteria, L. J. Cole and W. H. Wright conclude that descendants of a single cell constitute a pure-line, which cannot be modified by selection. Mutations occur in such lines, both spontaneously and in re- sponse to external stimulus. Much of the variation in bacterial cultures is attributable to isolation and perpetuation of certain pure-lines and the elimination of others. The study is reported in Jour. Infect. Diseases, 19, pp. 209-221. 